\title{
JUVENTUDE NEGRA PERIFÉRICA E DIREITO À CIDADE: UM ESTUDO DE CASO ${ }^{1}$
}

\author{
Daniel Victor Gouveia Lage ${ }^{2}$ \\ Daniela Abritta Cota $^{3}$
}

DOI: $10.5752 / P .2316-1752.2019 v 26 n 39 p 106$

\section{Resumo}

Este trabalho busca refletir sobre alternativas de planejamento urbano, a partir da percepção de jovens negros da periferia de São João del-Rei, MG. O estudo revelou que a vivência urbana desses sujeitos é restrita e violenta, tanto na periferia quanto na área central da cidade. Entretanto, apesar das dificuldades, a juventude negra periférica resiste por meio de manifestações socioculturais, vinculadas principalmente ao Hip-hop. Acredita-se que é preciso um novo tipo de planejamento, em que essas práticas sejam reconhecidas, viabilizando, de fato, o "direito à cidade" para esses indivíduos.

Palavras-chave: Vivência urbana. Juventude negra periférica. Direito à cidade. Planejamento insurgente.

\footnotetext{
1. E artigo tem por base a pesquisa realizada no Trabalho de Conclusão de Curso (TCC) do autor, no curso de Graduação em Arquitetura e Urbanismo da Universidade Federal de São João del-Rei (UFSJ), sob orientação de Daniela Abritta Cota.

2. Arquiteto e urbanista pela UFSJ. Contato: E-mail: daniel.gouveialage@gmail.com;

3. Arquiteta e urbanista pela UFMG, Mestra e Doutora em Geografia pela UFMG, Professora do curso de Graduação em Arquitetura e Urbanismo e do curso de Pós-graduação em Geografia da UFSJ. Contato: E-mail: abritta@ufsj.edu.br.
} 


\section{BLACK YOUTH ON THE OUTSKIRTS AND THE RIGHTTO THE CITY: A CASE STUDY}

\begin{abstract}
This work seeks to reflect on urban planning alternatives, based on the perception of young black people on the outskirts communities of São João del-Rei, MG. The study revealed that the urban experience of these subjects is quite restricted and violent, both on the outskirts and in the central areas of the city. However, despite the difficulties, the black youth on the outskirts resist through socio-cultural manifestations, mainly linked to Hip-hop. It is believed that a new type of planning is needed, in which these practices are recognized, in fact enabling the "right to the city" for these individuals.
\end{abstract}

Keywords: Urban living. Black youth on the outskirts. Right to the city. Insurgent planning.

\section{LA JUVENTUD NEGRA PERIFÉRICA Y EL DERE- CHO A LA CIUDAD: UN ESTUDIO DE CASO}

\section{Resumen}

Este trabajo busca reflexionar sobre las alternativas de planificación urbana, a partir de la percepción de los jóvenes negros de la periferia de São João del-Rei, MG. El estudio reveló que la experiencia urbana de estos sujetos es bastante restringida y violenta, tanto en la periferia como en las zonas centrales de la ciudad. Sin embargo, a pesar de las dificultades, la juventud negra de la periferia resiste por medio de manifestaciones socioculturales, principalmente vinculadas al Hip-hop. Se cree que se necesita un nuevo tipo de planificación, en el que se reconozcan estas prácticas, permitiendo el "derecho a la ciudad" para estas personas.

Palabras-Claves: Vida urbana. Juventud negra. Derecho a la ciudad. Planificación insurgente. 


\section{O direito à cidade lefebvriano e a perda de seu conceito original}

Rolnik (1995) considera a cidade uma obra social coletiva. Porém, sabe-se que nem todos têm acesso a ela na sua integridade. Nesse contexto, o conceito de "direito à cidade", estabelecido por Lefebvre (2001) vem permeando as discussões recentes sobre o planejamento urbano e busca o usufruto igualitário de todos os recursos existentes na cidade. Para o autor:

O direito à cidade se manifesta como forma superior dos direitos: direito à liberdade, à individualização na socialização, ao habitat e ao habitar. $\mathrm{O}$ direito à obra (atividade participante) e o direito à apropriação (bem distinto do direito à propriedade) estão implicados no direito à cidade (LEFEBVRE, 2001, p.134).

Segundo ele, "a vida urbana pressupõe encontros, confrontos das diferenças, conhecimentos e reconhecimentos recíprocos (inclusive no confronto ideológico e político) dos modos de viver, dos 'padrões' que coexistem na cidade" (LEFEBVRE, 2001, p. 22), ou seja, ela se fundamenta na diversidade e na coexistência dos diferentes grupos que nela residem. Entretanto, a cidade vem perdendo sua característica de integração e convivência social: ao adquirir um caráter capitalista, ela intensificou o "valor de troca" e se tornou um espaço de exploração e segregação (LEFEBVRE, 2001, p. 23). Nesse sentido, o 
"direito à cidade" só seria possível em outro modelo de sociedade, de caráter anticapitalista, em que prevaleceria o "valor de uso" e não o "valor de troca".

De acordo com a Carta Mundial pelo Direito à Cidade (2006, p. 1), estamos vivendo em um constante processo de urbanização em uma escala global nas últimas décadas - processo esse que tende a se intensificar nos próximos anos. Para Sanches, Sobreira e Araujo Junior (2017, p. 5), conforme cresce o número de pessoas residentes nas cidades, o número de conflitos sociais urbanos também aumenta, pois é no espaço urbano onde as desigualdades na distribuição de renda, de oportunidades, de poder político, de acessos aos bens e serviços públicos em geral, vão se tornar mais evidentes. Por isso, segundo os autores (2017, p. 6), a questão urbana se tornou uma temática bastante discutida internacionalmente, fazendo com que o conceito de "direito à cidade" fosse incorporado em alguns documentos internacionais, tornando-o um fundamento jurídico.

Isso também se refletiu no Brasil. A Constituição de 1988 incorporou em seu texto o princípio da função social da propriedade e dedicou um capítulo inédito sobre a política de desenvolvimento urbano, responsabilizando o poder público municipal pela elaboração do Plano Diretor, lei que determinaria diretrizes gerais para o desenvolvimento urbano local. Entretanto, somente treze anos depois é 
que houve a regulamentação desses dispositivos constitucionais, com a criação do Estatuto da Cidade em 2001. Apesar de o Estatuto evidenciar a questão do "direito à cidade", colocando-o como elemento central no sistema jurídico brasileiro, seus instrumentos não se propõem a romper com as estruturas de poder e opressão capitalistas e, por vezes, servem apenas para minimizar alguns problemas (SANCHES; SOBREIRA; ARAUJO JUNIOR, 2017, p. 8).

Ainda para os autores (2017, p. 10), a partir do momento em que o "direito à cidade" é assimilado pelo Estado e pelos sistemas jurídicos, esse conceito político-filosófico, construído por Lefebvre, de caráter revolucionário e anticapitalista, se perdeu, adquirindo um caráter jurídico acrítico, que não contesta as estruturas do sistema capitalista na qual a sociedade se baseia e as cidades se configuram, visando apenas a uma democratização simplista do acesso à cidade, sem considerar as especificidades dos vários grupos de indivíduos que nela habitam (classe, gênero, raça, sexualidade, faixa etária, etc.). Para que as desigualdades urbanas sejam amenizadas, é necessária a realização de propostas que possam integrar as demandas pelo "direito à cidade", que também reconheçam a diversidade social que compõe a cidade, buscando a igualdade de oportunidades para todos os indivíduos, sem discriminação. Isso diz respeito também à juventude negra periférica, que se encontra em situação de extrema 
vulnerabilidade social, destituída desse "direito à cidade" que é fundamental para o desenvolvimento pleno desse grupo social na sociedade.

\section{Juventude negra brasileira e as formas de vio- lência}

O Estatuto da Juventude, Lei brasileira n 12.852/2013, classifica como jovens as pessoas com idade entre $15 \mathrm{e}$ 29 anos de idade. Essa lei surge com o objetivo de instituir os direitos dos jovens e estabelece os princípios das políticas públicas voltadas para esse público. De acordo com o Censo Demográfico de 2010 (IBGE, 2010), o número de brasileiros que se encontram na faixa etária entre os 15 e 29 anos $^{4}$ corresponde a aproximadamente $27 \%$ da população.

A violência, em suas diferentes formas, é um dos principais motivos para a criação de políticas públicas voltadas para esse grupo populacional específico. Ela vai além de ações com caráter físico (violência física) e abrange também qualquer tipo de ação que viole psicologicamente, emocionalmente ou socialmente outra pessoa (violência simbólica).

\footnotetext{
4. Apesar de o IBGE considerar como jovem apenas a população com faixa etária entre os 15 e 24 anos, para esse estudo, iremos considerar a faixa etária definida pelo Estatuto da Juventude, que acrescenta os 5 anos posteriores (de 25 até os 29 anos) para a formação desse grupo populacional.
} 
Segundo Cerqueira (et al., 2018, p. 3), só nos últimos 10 anos, 553.000 pessoas morreram por causa da violência intencional no Brasil, notando-se uma enorme variação entre as unidades federativas, em que a situação é bastante grave nos estados das regiões Nordeste e Norte do país. Os autores $(2018$, p. 21) também contam que só em $2016,63,5 \%$ do total geral de óbitos por homicídios eram de jovens entre 15 e 29 anos, sendo que 94,6\% deles eram do sexo masculino.

O Índice de Vulnerabilidade Juvenil à Violência 2017 (IVJ 2017) apresenta dados relacionados à vulnerabilidade dos jovens brasileiros à violência. O IVJ também indica uma variável de cor/raça, levando em consideração as diferenças de mortalidade entre jovens brancos e negros no Brasil, com um indicador intitulado risco relativo (Gráfico 1), que é dado pela razão entre a taxa de mortalidade por homicídio entre os dois diferentes grupos. 


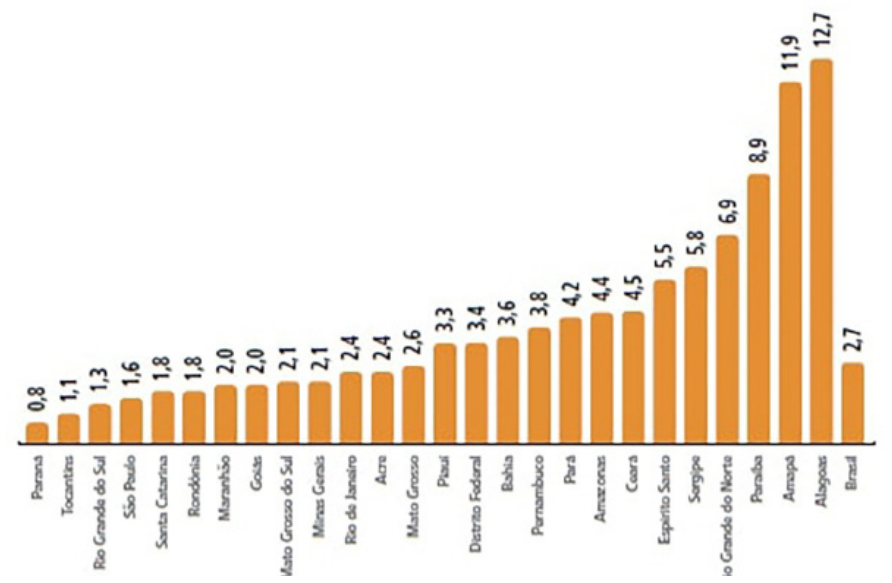

Gráfico 1 | A Risco relativo de um jovem negro ser vítima de homicídio em relação a um jovem branco, Brasil e UFs

Fonte: IVJ - Violência e Desigualdade Racial 2017, Ano base 2015; FBSP

Diante disso, percebe-se, claramente, a predominância em todo o Brasil de jovens negros entre as vítimas de homicídio se comparados aos jovens brancos na mesma faixa etária. Conforme a Secretaria de Governo (2017, p. 27), "em média, jovens negros têm 2,71 mais chances de morrerem por homicídio do que jovens brancos no país". Para agravar ainda mais a situação, estudos revelam que a desigualdade das mortes violentas por cor/raça vem aumentando nos últimos 10 anos e, de acordo com Cer- 
queira (et al. 2018, p. 4), "71,5\% das pessoas que são assassinadas a cada ano no país são pretas ou pardas".

No ano de 2015 foi realizada uma Comissão Parlamentar de Inquérito (CPI) no Senado Federal com o objetivo de investigar o assassinato de jovens no Brasil. Conclui-se que, de algum modo, os homicídios da juventude brasileira, em geral, e mais precisamente da juventude negra, estão relacionados à ação e/ou omissão do Estado Brasileiro (BRASIL, 2016, p. 146).

Seja pelo crescimento dos homicídios decorrentes de intervenção policial, muitas vezes nominado de autos de resistência; seja pela violência emergente do tráfico de drogas nas comunidades de baixa renda, resultado da ausência estatal; seja pelo racismo institucional que se infiltra nas instituições públicas e privadas. Como resultado, a população jovem negra vai sendo dizimada, com números que realmente se aproximam de uma guerra civil (BRASIL, 2016, p. 146).

Além disso, é necessário ressaltar que tais fatos estão relacionados ao racismo fortemente presente e estruturado na sociedade - apesar de esse racismo não estar tão explícito como no caso dos EUA. Segundo Florestan Fernandes (1964/1978), a configuração social brasileira produziu uma transição do modelo escravocrata para o modelo republicano sem alterar faticamente a situação da antiga relação de castas entre "senhores", "libertos" e "escravos". Além disso, tentou sustentar por muito tem- 
po a imagem de uma verdadeira "democracia racial". Na mesma linha, Lilia Schwarcz (2001) em sua pesquisa sobre o racismo brasileiro, endossa as críticas ao mito da "democracia racial." Além dos dados censitários que ajudam a desmascarar as desigualdades raciais persistentes na sociedade brasileira, a autora realizou uma pesquisa sobre a percepção que os/as brasileiros/as tinham com relação à experiência do racismo, concluindo que "todo brasileiro parece se sentir uma 'ilha de democracia racial', cercado de racistas por todos os lados" (Schwarcz, 2001, p. 76). Ao analisar a mestiçagem de nosso povo e as políticas de branqueamento posteriores à abolição da escravatura realizadas no Brasil no início do século XX, a autora afirma que produzimos um "racismo à brasileira", em que, mais do que com diferenças raciais, lidamos com diferenças na coloração da pele, as quais acabam por demarcar desigualdades sociais reconhecidas na intimidade. Dessa forma, Lilia Schwarcz corrobora a ideia de que ainda que o conceito raça já tenha sido desconstruído do ponto de vista biológico, ele continua ainda a ser um potente conceito descritivo e analítico das relações sociais. Isso significa dizer que em nossa sociedade de classes, o racismo desempenha um papel estruturante.

Silvio Luiz de Almeida, em sua obra intitulada "O que é racismo estrutural?", busca refletir sobre os conceitos de racismo como elemento estruturador das relações sociais. O autor (2018, p. 25) define racismo como "uma 
forma sistemática de discriminação que tem a raça como fundamento, e que se manifesta por meio de práticas conscientes ou inconscientes que culminam em desvantagens ou privilégios para indivíduos, a depender do grupo racial ao qual pertençam". Ainda segundo ele:

O racismo - que se materializa como discriminação racial - é definido pelo seu caráter sistêmico. Não se trata, portanto, de apenas um ato discriminatório ou mesmo de um conjunto de atos, mas de um processo em que condições de subalternidade e de privilégio que se distribuem entre grupos raciais se reproduzem no âmbito da política, da economia e das relações cotidianas (ALMEIDA, 2018, p. 27).

Outra autora que tem inegável pioneirismo na crítica ao racismo estrutural na sociedade brasileira por propor a articulação entre racismo e sexismo é Lélia Gonzalez. Em interlocução com o pensamento do psiquiatra martinicano Frantz Fanon - cuja obra sobre racismo e colonização é definida por ele como "estudo clínico" -, Lélia percebe muito cedo a necessidade de entrelaçar a desigualdade racial e social brasileira com as formações inconscientes, que ela observa serem exclusivamente brancas e europeias, operando uma denegação das nossas origens indígenas, latinas e africanas. É assim que ela identifica uma característica fundamental do "racismo à brasileira": voltar-se contra negros é denegar, no sentido freudiano, 
nossa amefricanidade - conceito cunhado pela autora (GONZALEZ, 1988).

Vários dados estatísticos revelam que "a raça é uma variável importante na explicação das desigualdades sociais, sobretudo quando se analisam o mercado de trabalho, educação, saúde" (BERNARDINO, GALDINO, 2004, p. 24). Tais desigualdades refletem na vivência cotidiana dos indivíduos no espaço urbano, sendo os negros os mais prejudicados. Para a Secretaria de Governo (2017, p. 47), é necessário "assumir que a violência letal está fortemente endereçada à população negra e que esse é um componente que se associa a uma série de desigualdades socioeconômicas". Portanto, para que essas desigualdades sejam anuladas, "políticas eficientes de prevenção da violência devem ser desenhadas e focalizadas, garantindo o efetivo direito à vida e à segurança da população negra no Brasil" (CERQUEIRA et al, 2018, p. 41), especialmente para o caso da juventude negra periférica.

Porém, tais dados não consideram a violência simbólica a que esses sujeitos estão submetidos, fruto do racismo estrutural, "à brasileira", reproduzido pela sociedade. Bordieu (2002) define a "violência simbólica" como uma forma de violência exercida sem o uso de ação física, afetando o sujeito violentado "moral e psicologicamente". Segundo ele, esse tipo de violência se estabelece na aceitação, por vezes inconsciente, de determinada impo- 
sição, que pode ser econômica, social, cultural, institucional ou simbólica. Silva e Oliveira (2017) apontam ainda que a violência simbólica é manifestada por diversas instituições da sociedade - a exemplo do Estado - que mantém o sistema segregacionista e normaliza a desigualdade social - algo que ocorre com os sujeitos negros e moradores das periferias urbanas.

Será verificado como essas formas de violência se manifestam para os jovens negros da periferia de São João del-Rei, MG.

\section{São João Del-Rei e a juventude negra periférica}

São João del-Rei está localizada no estado de Minas Gerais, a $184 \mathrm{~km}$ da capital Belo Horizonte. A cidade surgiu com a descoberta de ouro na margem esquerda do Rio das Mortes, por volta do ano 1705. Em 1713 ela se elevou a categoria de vila, e no ano de 1838 ela se tornou, oficialmente, cidade. Com a decadência da atividade mineradora, ela passou a se ocupar da agricultura e da pecuária. Posteriormente, a essas atividades somou-se a atividade industrial, (produtos metalúrgicos e têxteis) que passou a ter importância significativa na cidade. Entretanto, na década de 1960, com a transferência da industrialização para a região central do estado devido à recessão, São João del-Rei passou a intensificar suas atividades de prestação 
de serviços e de comércio (SANTOS, 2018, p. 37-38).

De acordo com Santos (2018, p. 43), "pelo seu passado aurífero e a forte presença negra, a cidade apresenta espaços com acessos diferenciados por grupos", pois, "enquanto grandes e imponentes igrejas estão localizadas no centro", (...) "os terreiros de candomblé e umbanda - religiões afro-brasileiras - estão situados na periferia da periferia, nos bairros mais afastados". Para a autora, o centro histórico de São João del-Rei, lugar para onde os olhares do poder público estão voltados, está cercado por aqueles que encontraram nas margens da cidade uma maneira de resistir e viver, mesmo que se tratando de uma São João del-Rei muito diferente da "oficial".

A autora, ao retratar a atual situação da população negra são-joanense, especificamente da mulher negra, aponta as desvantagens que negras (e negros também) possuem em relação a melhores condições de ocupação formal no mercado de trabalho, salário, nível de instrução e condições adequadas de saneamento. Segundo ela (SANTOS, 2018, p. 57), os dados "sintetizam parte das análises sobre relações de classe, raça e gênero. Se relações sociais são relações espaciais, então se pode entender que os dados apresentados se materializam na forma da cidade".

Atualmente, os dados mais recentes mostram que $42 \%$ dos habitantes residentes no distrito sede do município 
de São João del-Rei são negros, considerando pretos e pardos autodeclarados no Censo (IBGE, 2010). É possível observar no Mapa 1 que nos bairros Senhor dos Montes e Tijuco, conhecidos por serem bairros periféricos, por estarem localizados em áreas com algum tipo de risco ambiental e por serem carentes de infraestrutura urbana adequada e de serviços básicos de saúde, lazer e educação, a população negra é sobrerrepresentada, compondo mais da metade dos residentes nesses bairros. Já nos bairros centrais (Centro e Jardim Central), onde existe a concentração do comércio e dos serviços prestados e uma infraestrutura urbana de melhor qualidade, os negros representam apenas cerca de $1 / 4$ dos moradores. Em bairros semiperiféricos, ocupados principalmente pela classe média, que possuem alguns serviços públicos e estabelecimentos comerciais como supermercados, lojas, farmácias, etc., a taxa de habitantes negros fica próximo dos $40 \%$. 


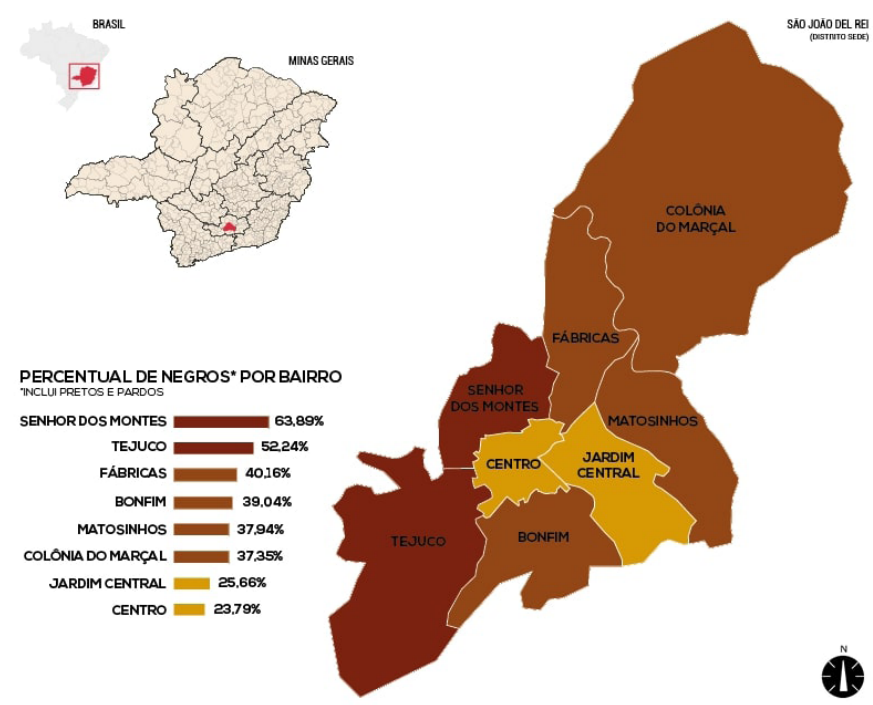

Figura 1 | Mapa da concentração da população negra em São João del-Rei, 2010 Fonte: Elaborado pelo autor com base nos dados do Censo Demográfico do IBGE, 2010

Segundo Santos (2018, p. 45), São João del-Rei é uma cidade que coloca os interesses do mercado em primeiro plano, por meio da articulação e imposição do poder público local, dos empresários e de promotores imobiliários. Apenas quem tem dinheiro para pagar por ela é que usufrui dos melhores lugares que ela tem para oferecer. Para os demais, que não possuem poder aquisitivo para custear esse "produto", restam somente as áreas periféricas da cidade, resultando na segregação socioespacial. Em 
São João del-Rei, assim como no restante do Brasil, não houve segregação oficial - como nos EUA -, por outro lado, houve omissão do Estado, nunca tentando integrar a população à cidade.

Essa desigualdade socioespacial é fruto de um processo histórico, estrutural e político conforme nos ensina Garcia (2009). Para a autora existe uma desigualdade racial nas cidades que se manifesta pela segregação espacial e pela segmentação social. A obra da autora reforça a necessidade e urgência de se pensar as desigualdades sociais para além da abordagem de classe social e demonstra que as questões urbanas devem ser analisadas também a partir da raça, pois comprova que esta é uma variável relevante para a compreensão das desigualdades que se revelam na organização espacial das cidades - algo que se buscou realizar nesse trabalho a partir da análise das vivências dos jovens negros na cidade.

\section{Vivências urbanas da juventude negra periféri- ca são-joanense: percepções e práticas.}

Para compreender melhor a vivência urbana da juventude negra periférica de São João del-Rei, foram utilizados como metodologia de pesquisa: a entrevista, o questionário e o mapa mental (RHEINGANTZ, et al, 2009). Tais metodologias visam apreender a experiência urbana vivi- 
da pelos jovens negros tanto nos bairros onde eles moram (periferia)quanto no restante da cidade (centro).

A periferia são-joanense ora abordada pode ser considerada um "território negro" (SODRÉ, 1988), na medida em que se refere ao lugar de "reconhecimento de si por outros" (SODRÉ, 1988, p. 14). Ou seja, "conhecer a exclusividade ou a pertinência das ações relativas a um determinado grupo implica também localizá-lo territorialmente". (SODRÉ, 1988, p. 23).

Assim, os relatos das vivências acabam refletindo relações de poder que se materializam no espaço. Os territórios negros - tomados aqui pelas periferias são-joanenses - diferenciam-se não apenas pela simples presença de pessoas negras, mas pelos processos de identificação territorial pelos quais essas pessoas apreendem aqueles espaços. Sendo assim, é possível falar de territórios negros mesmo quando se fala de espaços onde a população é majoritariamente negra, como no caso específico de São João del-Rei.

De um modo geral, em relação à segurança, percebe-se que, para esses jovens, independente da faixa etária, é tranquilo viver no bairro onde moram. Alguns deles se sentem seguros e confortáveis caminhando por ele; mas isso acontece porque a grande maioria sempre morou no mesmo bairro desde que nasceu e, por isso, eles conhe- 
cem os demais moradores e vice-versa: "Onde eu moro é sossegado, é bem tranquilo. Acho que é pelo fato de eu ter nascido lá e conhecer todo mundo desde sempre. Por isso eu me sinto bem seguro (E., 17 anos)".

Entretanto, as mulheres são as que mais afirmaram sentir certa insegurança e desconforto em caminhar pelo bairro, principalmente no período da noite, em que há menos movimento. Apenas um jovem, do gênero masculino, disse se sentir inseguro ao caminhar pelo bairro, e isso ocorre, segundo ele, por ser homossexual. Isso porque o lugar que ocupamos socialmente produz experiências distintas, especialmente se considerar a intersccionalidade entre raça, gênero e classe (OLIVEIRA, 2020).

A insegurança também aumenta quando pessoas "desconhecidas" começam a circular pelo bairro, por conta do tráfico de drogas. Essa movimentação de estranhos pelo bairro acaba gerando desconfiança e medo:

Eu sou mulher, né. Geralmente eu não me sinto segura andando em um monte de lugares. Mas aqui no bairro, eu me sinto segura, sim. Eu me sinto segura porque eu conheço a maioria das pessoas. Mas também depende da época. Às vezes nem todo mundo que tá na rua é gente daqui do bairro, às vezes vem gente de outro bairro, pessoas procurando outras coisas. Às vezes o bairro tá muito movimentado com coisa que não é legal. Aí vem outras pessoas pra cá, às vezes pessoas somem... Eu tô falando do tráfico em si, né. Quando tá bombando 
vem um pessoal muito estranho. Sempre tem um estranho andando na rua. E quando eles somem fica mais tranquilo (G., 20 anos).

O que se percebe é que existe certa contradição nessa relação de segurança e insegurança: ao mesmo tempo em que esses jovens se sentem seguros em caminhar pelo bairro, pelo fato de conhecerem os demais moradores e de se identificarem com o lugar, eles também evitam alguns lugares específicos e até mesmo são ensinados a evitá-los, porque são considerados perigosos, ou por serem ruas muito estreitas, pouco movimentadas e iluminadas, ou até mesmo por conta de serem conhecidas como áreas que pertencem ao tráfico de drogas:

O bairro não é tão perigoso assim, sabe. Não é tudo isso que se diz. Mas a gente é ensinado a tomar muito cuidado. Então tem alguns pontos específicos que a gente evita e toma um pouco mais de cuidado. E por isso acaba que às vezes a gente fica um pouco mais receoso de passar por alguns lugares do bairro. Entende a contradição? De um lado a gente é ensinado uma coisa, mas como eu conheço o bairro e as pessoas que moram nele, eu sei que não é tão assim (F., 29 anos).

Essa contradição em relação à segurança também aparece quando esses jovens contam da relação que eles possuem com outros bairros da cidade, principalmente com as áreas centrais. Alguns jovens dizem que se sentem 
um pouco mais seguros nesses bairros centrais porque existe um policiamento maior. Entretanto, a partir de determinado horário eles já não se sentem tão seguros, por conta do pouco movimento, do medo de desconhecidos e da reduzida ação da polícia. Já outros acreditam que a presença da polícia intimida, pois a abordagem policial é marcada de violência e é constante. L., 24 anos, relata: “Não me sinto seguro, quando vem a polícia, que vê a gente maloqueiro desse jeito e já chega junto. Toda hora a gente tá sendo abordado, mesmo quando tá tranquilo".

G., 20 anos, moradora do bairro Dom Bosco, aponta essa contradição no comportamento da polícia: "Essa coisa da segurança, é muito estranha também, porque são pessoas que deveriam fazer a nossa segurança. Mas a gente não se sente nem um pouco seguro". Para ela, a experiência vivida no Centro por muitos dos jovens negros da periferia de São João del-Rei é muito diferente da vivida nos bairros onde eles moram; mas, que em ambas, existe a violência: "A gente, enquanto pessoas pretas periféricas, a gente está num ambiente de violência em qualquer ambiente, seja na comunidade onde a gente mora, seja no Centro".

Ela também se refere à "violência simbólica" (BOURDIEU, 2002) que inibe o jovem periférico de circular pela cidade, como se certos espaços fossem "proibidos" para eles ou como se eles não devessem estar em determinados lugares: 
Quando eu tô na Rua da Cachaça, eu vejo jovens da mesma comunidade que eu, dando volta no quarteirão pra não ter que passar naquela rua, que é só atravessar no meio de pessoas e isso é tão violento, que a pessoa ela nem consegue, ela nem concebe a ideia de que: "Opa, por que eu vou dar essa volta, se eu posso passar aqui no meio dessa rua?". Mas não passa, porque mesmo sendo um lugar aberto, público, porque é uma rua, parece que é uma coisa demarcada (G., 20 anos).

Tem uns olhares, principalmente com a questão do cabelo. Eu reparo muito. Por mais que você não saiba o que as pessoas estão pensando, pela expressão facial delas você percebe (F., 29 anos).

Uma vez no Centro, na fila da Casa Lotérica, umas senhoras ficaram olhando estranho pra mim. Uma pessoa de cima (dos bairros periféricos altos) é olhada diferente no Centro. Principalmente pessoas negras $\left(H_{\text {., }} 20\right.$ anos).

Para D., arte-educador negro são-joanense, a cidade limita o espaço de ação dos jovens negros de um jeito muito cruel, principalmente dos mais novos. Em São João del-Rei, onde o passado escravocrata ainda é muito presente no imaginário da população, são muito bem colocados os lugares em que esses jovens negros podem e não podem ir. "Se a gente tá falando de um corpo, que tem toda uma construção de uma narrativa que coloca ele num lugar subalternizado pela sociedade, ele aprende a se ver 
assim. Ele aprende que a sociedade o vê assim". É uma estrutura que pretende manter esse corpo subalternizado no espaço. A função desse corpo negro é trabalhar, servir como mão de obra barata. O direito ao lazer lhe é negado.

De acordo com Almeida (2013, p. 156), a relação que os jovens periféricos estabelecem com as áreas centrais da cidade é diferente da relação com o bairro onde vivem, no qual existe um sentimento de pertencimento, de identificação ao lugar. Sair do bairro onde moram significa transitar pela cidade, e muitos desses jovens têm certo receio de andar pelo centro da cidade ou por outros lugares distantes do seu local de origem - do seu território, no dizer de Sodré (1988). Para aquele autor (ALMEIDA, 2013, p. 157), "o bairro apresenta-se para os jovens como uma referência, um espaço que proporciona certa segurança, mesmo que seja conhecido na cidade pelo alto índice de violência", onde essa relação de pertencimento é demonstrada na forma como esses jovens chamam o lugar: "pedaço," "quebrada", "comunidade". Apesar de esses jovens possuírem relações afetivas com o bairro, principalmente por conta dos moradores, amigos e vizinhos, e dos movimentos culturais e religiosos que ali existem, eles também pontuaram que a questão da violência e do tráfico de drogas, além da distância de grandes supermercados e a falta de infraestrutura (asfalto e iluminação) em alguns lugares, são fatores que fazem com que a vida na periferia seja mais custosa. 


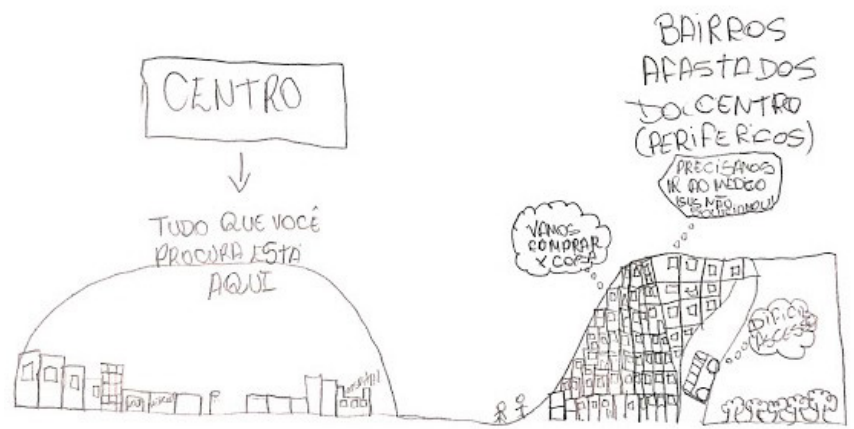

Figura 2 | Mapa Mental de H., 20 anos, moradora do bairro Dom Bosco Fonte: LAGE, 2019, p.69

O mapa mental de H., 20 anos, moradora do bairro Dom Bosco, é um ótimo exemplo para demonstrar a desigualdade existente entre centro e periferia no que diz respeito à oferta de serviços e comércio, obrigando esses jovens a se deslocarem até o centro para ter acesso aos serviços. Porém, a articulação entre Centro e Periferia é bastante complicada, seja pela topografia, seja pela escassez e pelo preço (alto) do transporte público. Assim, a mobilidade urbana desse público é precária. Prova disso é que $62 \%$ desses jovens costumam andar a pé, enquanto que $30 \%$ costumam usar da bicicleta como principal meio de transporte e $8 \%$ usam skate como alternativa. O transporte público é a última alternativa: "Raramente eu pego o ônibus. Só quando tá chovendo e não tem outra opção. Ônibus é muito caro aqui na cidade, né. E a cidade, querendo ou não, é uma cidade pequena (G., 20 anos)." 
Entretanto, apesar de todas as adversidades em que se encontra a juventude negra periférica são-joanense, ela ainda resiste por meio de manifestações sociais, culturais, artísticas e, também, políticas, vinculadas principalmente com o Movimento Hip-hop da cidade. "Nós, jovens da periferia estamos gritando para ser vistos. A gente tá gritando por oportunidades e a cidade tá fechando os olhos pra isso" (SANTOS, 2018a apud SANTOS, 2012, p. 81) ${ }^{5}$. Enquanto arte-educador, D. acredita que a juventude negra periférica tem uma corporeidade muito expressiva; pois, como ela presencia toda essa dinâmica de poder, ela tem uma atuação vigorosa diante dessa situação: "Quando esse corpo, que é subalternizado, ele se coloca de uma forma libertária frente a esse sistema, ele rompe uma estrutura de opressão, uma estrutura de opressão não só do corpo dele, mas também do corpo do outro".

Dessa forma, foi assim que alguns desses jovens negros periféricos, inconformados com essa situação, começaram a se articular por meio do Movimento Hip-hop, encontrando-se em lugares centrais e espaços públicos da cidade pra se reunirem e fazer Rap. Surgiu então o Rap na Bika, que de acordo com G., começou com a inquietação de meninos periféricos que iam pro Centro: "o T. se encontrava com amigos na Praça da Estação pra batalhar, e aí quando viu foi chegando muita gente. Daí decidiu fazer

5. SANTOS, D. Entrevista concedida a Bruna Lúcia dos Santos. São João del-Rei, 25 abr. 2018a 
um evento, da batalha, um evento. Então foram pra Praça da Biquinha, por isso que chama Rap na Bika, fizeram lá". G. conta que o projeto existe há aproximadamente 4 anos; e que, apesar de ter sido idealizado e iniciado por T. e outros rapazes, atualmente a organização é totalmente composta por mulheres. Uma série de atividades é desenvolvida: oficinas para as crianças, rodas de conversas para as mães, apresentações de artistas locais, exibições de curtas e, claro, as famigeradas batalhas de rap.

Almeida (2013, p. 158) conta que para os jovens ligados ao Movimento Hip-hop, o bairro enquanto "quebrada" é ainda mais forte, pois se tornou um posicionamento político falar da periferia, da "quebrada". Para o autor (2013, p. 159), essa associação do bairro, o local, a um grupo mais geral, intitulado "periferia", fez com que os limites territoriais e geográficos fossem rompidos, possibilitando certa interação e cooperação entre jovens de vários bairros distantes do centro. Esse fenômeno também ocorre com o Rap na Bika. G. conta que, por mais que a grande maioria do público seja do bairro Tijuco, pessoas de outros bairros também participam do evento.

De acordo com Silva (2007, p. 6), "a experiência de vida na localidade é o que confere legitimidade política ao discurso musical. Os rappers assumem, assim, a condição de porta-vozes de um universo silenciado pelos meios de comunicação e ignorado pelo poder público." F., 29 anos é MC. Ela faz parte do Movimento Hip-hop são-joanense 
há 12 anos. Começou no Break e há 4 anos atua como rapper. Para ela, estar no Centro é se afirmar, é resistir. É ocupar espaços que lhes são negados com o intuito de romper com esses discursos de opressão: "É uma forma de falar isso aqui é o nosso espaço, a gente não vai continuar isolado na periferia onde vocês delegaram como sendo nosso espaço, não. A gente vai chegar e ocupar".
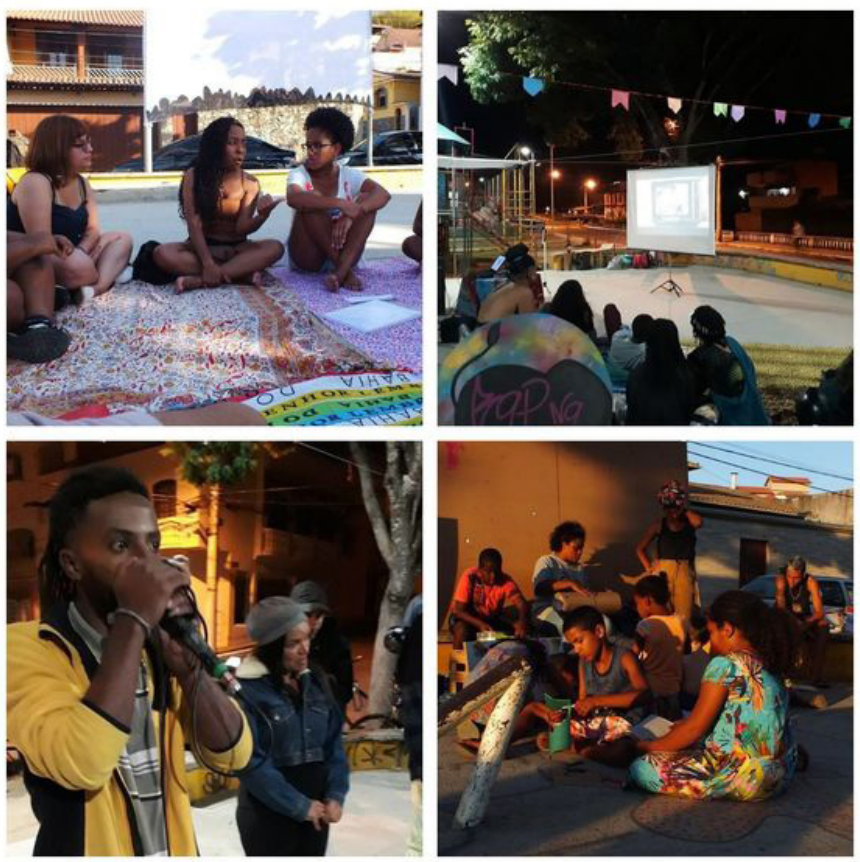

Figura 3 | Atividades realizadas pelo Rap na Bika

Fonte: <https://www.facebook.com/rapnabika/>. Acesso em 08 jun. 2019 
G., 20 anos, que é uma das organizadoras do Rap na Bika conta das dificuldades que o grupo tem encontrado para a realização do evento, principalmente por conta da burocracia envolvida e da falta de apoio da Prefeitura, e afirma: "Os órgãos públicos não consideram a gente importante. Acha que é um bando de gente que não tem nada pra fazer, quando na verdade somos apenas jovens, mulheres e crianças procurando ter algum momento de lazer na cidade".

Segundo Almeida (2013, p. 165), essa geração de jovens cria relações muito próximas entre lazer e participação, onde o lazer é considerado não apenas um direito, mas também uma plataforma política; que serve para esses jovens se encontrarem uns com os outros e se expressarem diante da sociedade. Trata-se também da luta por outros "territórios negros" na cidade (SODRÉ, 1988) impregnada de marcadores culturais e simbólicos desse grupo. Segundo Raffestin (1993, p. 53), os territórios negros não são fruto de um isolamento autoinduzido ou sem motivação, e sim uma "forma de defesa" já que "onde há poder, há resistência".

Para Almeida (2013, p. 170), "é como se o 'direito à cidade', assumido há tempos como bandeira de diferentes grupos juvenis periféricos da metrópole tenha se transformado em direito à cultura". Ainda, "pensar a resistência pela cultura é compreender que a ação política adentrou o cotidiano e, por outro lado, que a cultura se faz presente 
neste cotidiano" (ALMEIDA, 2013, p. 167).

\section{Apontamentos finais: por um direito à cidade lefebvriano}

De acordo com Almeida (2013, p. 161), “a apropriação da cidade, de seus espaços e equipamentos, constitui-se como um elemento fundamental da condição juvenil contemporânea", pois a circulação pela cidade e o acesso ao que ela oferece transformaram-se em demandas, mostrando, da parte de alguns desses coletivos, a necessidade da criação de políticas públicas. Entretanto, é importante salientar que tais políticas não podem somente trabalhar no sentido de subverter a lógica do estereótipo de uma juventude descompromissada e irresponsável e de que o Estado é o único capaz de criar e gerenciar tais políticas. Ações que valorizam práticas culturais da juventude negra, apesar de importantes, especialmente por demarcarem "territórios negros", como forma de enfrentamento ao racismo, os mantêm à margem da cidade (ou seja, se concentram nas periferias), não garantindo a esses sujeitos o "direito à cidade" no sentido proposto por Lefebvre. As áreas centrais da cidade ainda vão continuar sendo "a cidade", ou seja, aquela parte da cidade em que esses jovens não terão acesso e nem o direito de circular por ela. 
Enquanto planejadores precisamos repensar as políticas que, por mais bem-intencionadas e inovadoras sejam, correm o risco de apenas "democratizar" a cidade sem de fato romper com as estruturas de opressão presentes no espaço urbano. Para Miraftab (2016, p. 366), “o planejamento como o conhecemos está se defrontando com uma crise de legitimidade. Suas contradições e falsas promessas manifestam-se em crescentes desigualdades"; por isso "necessitamos considerar essas práticas seriamente e reconhecê-las como instâncias do fazer a cidade, como exemplos das pessoas planejando seus próprios futuros, um futuro que corporifica um urbanismo humano" (2016, p. 367).

Segundo a autora (2016, p. 368), um planejamento insurgente seria um modelo alternativo em que as práticas cidadãs também seriam reconhecidas como formas de planejamento. O planejamento insurgente e os agentes envolvidos em suas práticas buscam uma inclusão por meio da autodeterminação, em que os direitos das pessoas são de fato efetivados. Acredita-se que o planejamento insurgente seja uma das principais alternativas capazes de efetivar o "direito à cidade" revolucionário e anticapitalista defendido por Lefebvre.

Dessa maneira, como o conceito de "direito à cidade" de Lefebvre foi esvaziado com a sua inserção aos sistemas jurídicos estatais, os movimentos sociais insurgentes correm o risco de perderem o seu significado e, assim, 
desaparecer. É preciso que nós, enquanto planejadores, sejamos cuidadosos ao nos aproximar dos movimentos sociais, entendendo o nosso lugar enquanto apenas agentes coadjuvantes e apoiadores, evitando apagar o protagonismo dos seus dirigentes.

Para que o "direito à cidade" seja amplamente assegurado a todas e todos, é necessário que todas e todos estejam engajados nessa luta, independente da cor/ raça, gênero, sexualidade, faixa etária, condição social e origem. É importante que todos tenham espaço para se autoafirmar e, assim, apresentar as suas pautas e lutar pelos seus direitos. Principalmente a juventude negra e periférica, que mesmo estando em situação de extrema vulnerabilidade social, demonstra um enorme potencial como agente transformador da sociedade. Nesse sentido, conclui-se esse trabalho concordando com Gabriela Leandro quando afirma que:

(...) nesse país Brasil, tão vasto, a arquitetura, o urbanismo e o planejamento urbano foram e ainda são peças fundamentais para manutenção das opressões nas cidades. Embora imaginar e construir territórios sejam práticas históricas inerentes à população negra do lado de cá do Atlântico, o racismo, essa tecnologia que opera o mecanismo de morte, continua a produzir a desumanização de determinados sujeitos, corroborando para a desclassificação de sua propriedade no fazer cidade. O racismo neutraliza o constrangimento da eliminação do outro, e de suas faculdades. Reconhecer a sua existência estrutural e encará-la de frente parece ser o único caminho viável para que seja profícuo o encontro entre 
o direito à cidade e as questões raciais, vislumbrando a conciliação para uma vida comum possível (LEANDRO, 2019, p. 07).

\section{Referências}

ALMEIDA, Renato Souza de. Juventude, direito à cidade e cidadania cultural na periferia de São Paulo. Revista do Instituto de Estudos Brasileiros, Brasil, n. 56, p. 151-172, jun. 2013.

ALMEIDA, Silvio Luiz de. O que é racismo estrutural? Belo Horizonte: Letramento, 2018.

BERNADINO, Joaze; GALDINO, Daniela (Org.). Levando raça a sério: Ação afirmativa e universidade. Rio de Janeiro: DP\&A, 2004.

BORDEAU, Pierre. A dominação masculina. Rio de Janeiro: Bertrand Brasil, 2002.

BRASIL.Presidência da República. Secretaria de Governo. Índice de vulnerabilidade juvenil à violência 2017: desigualdade racial, municípios com mais de 100 mil habitantes. São Paulo: Fórum Brasileiro de Segurança Pública, 2017.

BRASIL. Senado Federal. CPI Assassinato de Jovens. Brasília, 2016.

BRASIL.Senado Federal. Estatuto da juventude: atos internacionais e normas correlatas. Brasília, 2013.

CERQUEIRA, Daniel et al. Atlas da Violência 2018. Rio de Janeiro: IPEA/FBSP, 2018.

FERNANDES, F. A integração do negro na sociedade de classes (3 ${ }^{a}$ ed.). São Paulo: Àtica. 1978. (Original publicado em 1964) FÓRUM SOCIAL MUNDIAL. Carta Mundial Pelo Direito à ci- 
dade. Bamako, Caracas e Karachi, 12 jun. 2006.

GARCIA, Antônia dos Santos. Desigualdades raciais e segregação urbana em capitais antigas: Salvador, cidade D'Oxum e Rio de Janeiro, cidade de Ogum. Rio de Janeiro: Garamond, 2009.GONZALEZ, Lélia. A categoria político-cultural de amefricanidade. In: Tempo Brasileiro. Rio de Janeiro, No. 92/93 (jan./jun.) p. 69-82,1988.

INSTITUTO BRASILEIRO DE GEOGRAFIA E ESTATÍSTICA. CensoDemográfico2010 - São João del-Rei (MG). Disponível em: <https://cidades.ibge.gov.br/brasil/mg/ sao-joao-del-rei>. Acesso em: 06 abr. 2019.

LAGE, Daniel Victor Gouveia. Juventude negra e o direito à cidade: Um estudo sobre a vivência de jovens negros da periferia em São João del-Rei - MG. 2019. 130 f. TCC (Graduação) - Curso de Arquitetura e Urbanismo, Universidade Federal de São João del-Rei, São João del-Rei, 2019.

LEANDRO, Gabriela. Direito à cidade e questões raciais. Revista COLETIVA. Dossiê 24 - Direito à Cidade. Fev. Mar. Abr. Mai. p.01-10, 2019.

LEFEBVRE, Henri. O direito à cidade. São Paulo: Centauro, 2001.

MIRAFTAB, Faranak. Insurgência, planejamento e a perspectiva de um urbanismo humano. Revista Brasileira de Estudos Urbanos Regionais. Recife: 2016

OLIVEIRA, Ana Caroline Amorim. Lélia Gonzalez e o pen- 
samento interseccional: uma reflexão sobre o mito da democracia racial no Brasil. Interritórios - Revista de Educação Universidade Federal de Pernambuco, Caruaru, BRASIL. V.6 N.10, p.89-104, 2020.

Educação Universidade Federal de Pernambuco, Caruaru, BRASIL. V.6 N.10, p.89-104, 2020.

RAFFESTIN, Claude. Por uma Geografia do Poder. São Paulo: Ática, 1993.

RHEINGANTZ, P. A. et al. Observando a qualidade do lugar: procedimentos para a avaliação pós-ocupação. Rio de Janeiro: Universidade Federal do Rio de Janeiro, Faculdade de Arquitetura e Urbanismo, Pós-Graduação em Arquitetura, 2009.

ROLNIK, Raquel. O que é cidade. São Paulo: Brasiliense, 1995.

SANCHES, Jussara Romero; SOBREIRA, Gabriel Miaki; ARAUJO JUNIOR, Miguel Etinger de. De Lefevre a Harvey: uma análise crítica do direito à cidade como instituto jurídico. Organizações e Sustentabilidade, Londrina, v. 5, n. 1, p. 3-19, set. 2017.

SANTOS, Bruna Lúcia dos. O lugar da mulher negra no espaço urbano: da segregação socioespacial à resistência no bairro São Dimas em São João del-Rei - MG. 2018. 99 f. TCC (Graduação) - Curso de Geografia, Universidade Federal de São João del-Rei, São João del-Rei, 2018.

SCHWARCZ, Lilia Moritz. Racismo no Brasil. São Paulo: Publifolha, 2001 .

SILVA, José Carlos Gomes Da. Juventude e segregação urbana na cidade de São Paulo: os números da vulnerabilidade juvenil e a percepção musical dos rappers. Ponto Urbe (online), 2007.Disponível em: <http://pontourbe.revues.org/1250>. Acesso em: 14 set. 2019

SILVA, L. F; OLIVEIRA, L. O papel da violência simbólica na so- 
ciedade por Pierre Bourdieu. Rev. FSA, Teresina, v.14, n.3, art. 9, p. 160-174, mai./jun. 2017.

SODRÉ, Muniz. O Terreiro e a Cidade: a forma social negro-brasileira. Petrópolis: Vozes, 1988.

$=$ 